\title{
Micro-fabricated scaffolds lead to efficient remission of diabetes in mice
}

Citation for published version (APA):

Buitinga, M., Assen, F., Hanegraaf, M., Wieringa, P., Hilderink, J., Moroni, L., Truckenmüller, R., van Blitterswijk, C., Roemer, G-W., Carlotti, F., de Koning, E., Karperien, M., \& van Apeldoorn, A. (2017). Micro-fabricated scaffolds lead to efficient remission of diabetes in mice. Biomaterials, 135, 10-22. https://doi.org/10.1016/j.biomaterials.2017.03.031

Document status and date:

Published: 01/08/2017

DOI:

10.1016/j.biomaterials.2017.03.031

Document Version:

Publisher's PDF, also known as Version of record

Document license:

Taverne

Please check the document version of this publication:

- A submitted manuscript is the version of the article upon submission and before peer-review. There can be important differences between the submitted version and the official published version of record.

People interested in the research are advised to contact the author for the final version of the publication, or visit the DOI to the publisher's website.

- The final author version and the galley proof are versions of the publication after peer review.

- The final published version features the final layout of the paper including the volume, issue and page numbers.

Link to publication

\footnotetext{
General rights rights.

- You may freely distribute the URL identifying the publication in the public portal. please follow below link for the End User Agreement:

www.umlib.nl/taverne-license

Take down policy

If you believe that this document breaches copyright please contact us at:

repository@maastrichtuniversity.nl

providing details and we will investigate your claim.
}

Copyright and moral rights for the publications made accessible in the public portal are retained by the authors and/or other copyright owners and it is a condition of accessing publications that users recognise and abide by the legal requirements associated with these

- Users may download and print one copy of any publication from the public portal for the purpose of private study or research.

- You may not further distribute the material or use it for any profit-making activity or commercial gain

If the publication is distributed under the terms of Article $25 \mathrm{fa}$ of the Dutch Copyright Act, indicated by the "Taverne" license above, 


\title{
Micro-fabricated scaffolds lead to efficient remission of diabetes in mice
}

\author{
Mijke Buitinga a, b, Frank Assen ${ }^{\text {a }}$, Maaike Hanegraaf ${ }^{c}$, Paul Wieringa ${ }^{\mathrm{d}}$, \\ Janneke Hilderink ${ }^{a}$, Lorenzo Moroni ${ }^{\mathrm{d}}$, Roman Truckenmüller ${ }^{\mathrm{d}}$, \\ Clemens van Blitterswijk ${ }^{\mathrm{d}}$, Gert-Willem Römer ${ }^{\mathrm{e}}$, Françoise Carlotti ${ }^{\mathrm{c}}$, \\ Eelco de Koning c, f, g, Marcel Karperien a , Aart van Apeldoorn a, d, *
}

a Department of Developmental BioEngineering, MIRA Institute for Biomedical Technology and Technical Medicine, University of Twente, Enschede, The Netherlands

${ }^{\mathrm{b}}$ Department of Radiology and Nuclear Medicine, Radboud UMC, Nijmegen, The Netherlands

${ }^{\mathrm{c}}$ Department of Nephrology, Leiden University Medical Centre, Leiden, The Netherlands

${ }^{\mathrm{d}}$ Complex Tissue Regeneration Department, MERLN Institute for Technology Inspired Regenerative Medicine, Maastricht University, Maastricht, The Netherlands

e Department of Applied Laser Technology, University of Twente, Enschede, The Netherlands

${ }^{\mathrm{f}}$ Department of Endocrinology, Leiden University Medical Centre, Leiden, The Netherlands

${ }^{\mathrm{g}}$ Hubrecht Institute-Royal Netherlands Academy of Arts and Sciences (KNAW) and University Medical Center Utrecht, Utrecht, The Netherlands

\section{A R T I C L E I N F O}

\section{Article history:}

Received 15 January 2017

Received in revised form

19 March 2017

Accepted 21 March 2017

Available online 27 March 2017

\section{Keywords:}

Diabetes

Islet

Transplantation

Microwell scaffolds

\begin{abstract}
A B S T R A C T
Despite the clinical success of intrahepatic islet transplantation in treating type 1 diabetes, factors specific to this transplantation site hinder long-term insulin independence. The adoption of alternative, extravascular sites likely improve islet survival and function, but few locations are able to sufficiently confine islets in order to facilitate engraftment. This work describes a porous microwell scaffold with a well-defined pore size and spacing designed to guarantee islet retention at an extrahepatic transplantation site and facilitate islet revascularization. Three techniques to introduce pores were characterized: particulate leaching; solvent casting on pillared wafers; and laser drilling. Our criteria of a maximum pore diameter of $40 \mu \mathrm{m}$ were best achieved via laser drilling. Transplantation studies in the epididymal fat of diabetic mice elucidated the potential of this porous scaffold platform to restore blood glucose levels and facilitate islet engraftment. Six out of eight mice reverted to stable normoglycemia with a mean time to remission of $6.2 \pm 3.2$ days, which was comparable to that of the gold standard of renal subcapsular islet grafts. In contrast, when islets were transplanted in the epididymal fat pad without a microwell scaffold, only two out of seven mice reverted to stable normoglycemia. Detailed histological evaluation four weeks after transplantation found a comparable vascular density in scaffoldseeded islets, renal subcapsular islets and native pancreatic islets. However, the vascularization pattern in scaffold-seeded islets was more inhomogeneous compared to native pancreatic islets with a higher vascular density in the outer shell of the islets compared to the inner core. We also observed a corresponding decrease in the beta-cell density in the islet core. Despite this, our data indicated that islets transplanted in the microwell scaffold platform were able to maintain a viable beta-cell population and restore glycemic control. Furthermore, we demonstrated that the microwell scaffold platform facilitated detailed analysis at a subcellular level to correlate design parameters with functional physiological observations.
\end{abstract}

(c) 2017 Elsevier Ltd. All rights reserved.

\footnotetext{
* Corresponding author. Complex Tissue Regeneration Department, Institute for Technology Inspired Regenerative Medicine (MERLN), Maastricht University, Maastricht, The Netherlands.
}

E-mail address: a.vanapeldoorn@maastrichtuniversity.nl (A. van Apeldoorn).

\section{Introduction}

The transplantation of islets of Langerhans from donor pancreata into the liver has become an established therapy for a subpopulation of patients with type 1 diabetes and labile glycemic 
control [1]. Although the clinical outcome of this islet transplantation approach has improved over the last decade, progressive islet loss in the post-transplantation period often prevents longterm insulin independence to only a subset of patients [2]. One advantage of the intrahepatic site has been the ease of islet delivery, achieved by islet infusion into the portal vein. However, this exposes islets directly to blood and elicits the instant blood-mediated inflammatory reaction (IBMIR). This has been shown to cause islet destruction and islet loss $[3,4]$. In addition, the hepatic environment imposes additional challenges and stress to islet engraftment and survival, such as the exposure to reduced oxygen tension $[5,6]$ and high concentrations of immunosuppressants [7].

While these limitations can be partly overcome by employing extrahepatic extravascular transplantation sites, these sites are typically challenged by limited space to transplant sufficient amount of islets, the inability to restrict islet migration, or poor vascularization [8]. These challenges have driven the field towards engineering efficient and tailored transplant microenvironments using biomaterials that ensure optimal islet spatial distribution and promote revascularization [9-11].

Pancreatic islets are highly vascularized by a dense network of capillaries. This capillary network is not only crucial for an adequate nutrient supply, but it is also critical for glucose sensing and the rapid secretion of islet hormones into the blood stream [12]; islets with vascular defects do not regulate blood glucose levels properly $[12,13]$. These requirements dictate that an islet tissue engineered construct should allow for high mass transport and good vascularization, implying the creation of a porous implantable construct that permits blood vessel infiltration. However, recent findings report that it is a narrow range of pore size, $30-40 \mu \mathrm{m}$, that maximizes vascularization [14], suggesting that having precise control over pore size would greatly facilitate revascularization of an implantable scaffold.

Recently, we have developed a novel polymer film-based microwell scaffold platform for islet transplantation that provides a mechanically protective environment while maintaining islet morphology and islet functionality in vitro [15]. In the current study, we sought to further optimize this scaffold platform to promote islet engraftment in vivo by facilitating vascular tissue ingrowth via introduction of well-defined pores with a maximum diameter of $40 \mu \mathrm{m}$. Therefore, we have evaluated the feasibility of three process sequences based on substrate modification and replication by (micro)thermoforming (SMART) [16] in conjunction with the following methods to introduce pores with controlled dimensions and spacing in polymer films: 1) particulate leaching using salt crystals; 2) solvent casting on patterned silicon wafers; and 3) laser drilling using an ultra-short pulsed laser source, of which laser drilling best matched our design criteria. As a first step in identifying the in vivo potential of this porous microwell scaffold for extrahepatic islet transplantation, we have investigated whether this highly flexible and tunable platform can support islet function and engraftment in a diabetic mouse model.

\section{Materials and methods}

\subsection{PEOT/PBT thin film fabrication}

Scaffolds were fabricated from a poly(ethylene oxide terephtalate)/poly(butylene terephthalate) block copolymer with composition 4000PEOT30PBT70 (PolayActiveTM, IsoTis Orthobiologics S.A., Irvine, USA) as previously described [15]. A 15\% (w/w) polymer solution was prepared in $35 \%(\mathrm{w} / \mathrm{w})$ 1,1,1,3,3,3-hexafluoro2-isopropanol (Biosolve, Valkenswaard, The Netherlands) and 65\% (w/w) chloroform (Merck, Darmstadt, Germany). The polymer solution was cast on silicon wafers at a height of $200 \mu \mathrm{m}$, finally resulting in $\sim 15 \mu \mathrm{m}$ thick films. The films were placed under nitrogen-flow for $12 \mathrm{~h}$, incubated in ethanol overnight to remove solvent residue, and dried in a vacuum oven (Heraeus, Hanau, Germany) at $30{ }^{\circ} \mathrm{C}$ for 3 days.

\subsection{Microwell scaffold fabrication and characterization}

Microwell scaffolds consisted of a thin PEOT/PBT polymer film patterned with microwells and a porous lid with $\sim 40 \mu \mathrm{m}$ pores. Microthermoforming [17] was employed to create the microwell structure into PEOT/PBT thin polymer films as described previously [15]. In short, a heated polymer film was pressed into a stainless steel mold (produced by Lightmotif BV, Enschede, The Netherlands) using polyethylene films as backing material. Molding temperature and pressure were $85{ }^{\circ} \mathrm{C}$ and $45 \mathrm{kN}$, respectively. Pore geometry and architecture were characterized by scanning electron microscopy (SEM, Philips XL 30 ESEM-FEG, Eindhoven, The Netherlands). Scaffolds were gold sputter coated (Cressington, UK) prior to SEM analysis. Pore dimensions were measured in three different samples per type of scaffold at the side, rim and bottom of the microwells using ImageJ software (http://rsb.info.nih.gov/ij/).

\subsection{Particulate leaching}

To fabricate porous microwell scaffolds by particulate leaching, sodium chloride crystals were added to the polymer solution just before solvent casting. The crystals were manually grinded and sieved on an automatic shaker (sieve range 38-63 $\mu \mathrm{m}$ ). Three different salt-to-polymer ratios were tested: $1: 2,1: 1.5$, and 1:1. After scaffold fabrication by microthermoforming, the scaffolds were leached in demi-water at $50{ }^{\circ} \mathrm{C}$ for 4 days. To assess whether residual sodium chloride crystals were present, $\mathrm{C}$ and $\mathrm{O}$ (the polymer) and $\mathrm{Na}$ and $\mathrm{Cl}$ atoms were mapped using a SEM integrated energy dispersive spectrometer (EDS, EDAX, AMETEK Materials Analysis Division, Mahwah, USA).

\subsection{Pillared wafer}

To fabricate porous microwell scaffolds using microfabrication techniques, silicon wafers patterned with micropillars were produced. For this purpose, a chromium-glass mask was designed for patterning photoresist on the wafers. The photomask design contained circular features to produce a grid pattern of pillars with a diameter of $\sim 20,30$, and $40 \mu \mathrm{m}$, spaced at $200 \mu \mathrm{m}$. Process flow design, lithography and etching were done by ThermoFisher (ThermoFisher Scientific Inc., Enschede, The Netherlands). Briefly, single side-polished wafers ( $100 \mathrm{~mm}$ diameter, $525 \mu \mathrm{m}$ thick) were oxidized to a thickness of $1 \mu \mathrm{m}$. Photoresist OiR 907-17 was patterned using the abovementioned mask using an $\mathrm{EVG}^{\mathbb{R}} 620$ Automated Mask Alignment System (EV Group, St. Florian am Inn, Austria). The oxide masking layer was etched by a reactive ion etching (RIE) step. To form pillars of a height of $75 \mu \mathrm{m}$, a deep RIE (DRIE) step was performed. The photoresist and passivation layer were stripped and the wafer was cleaned in a Piranha solution $\left(\mathrm{H}_{2} \mathrm{SO}_{4}: \mathrm{H}_{2} \mathrm{O}_{2}=3: 1(\mathrm{v} / \mathrm{v})\right)$. To improve demolding of the thin PEOT/ PBT films, pillared wafers were coated with trichloro $(1 \mathrm{H}, 1 \mathrm{H}, 2 \mathrm{H}$, $2 \mathrm{H}$-perfluorooctyl)silane (Sigma Aldrich, USA). The polymer solution was cast at a height of $90 \mu \mathrm{m}, 15 \mu \mathrm{m}$ above the pillars, to ensure perforation of the film during solvent evaporation and subsequent thinning of the polymer film. The porous polymer films were used for microwell scaffold fabrication.

\subsection{Laser drilling}

To produce porous microwell scaffolds by laser drilling, an 
Yb:YAG laser source (TruMicro 5050, Trumpf GmbH, Germany) with a fixed pulse duration of about $7 \mathrm{ps}$, a maximum pulse frequency of $400 \mathrm{kHz}$, and a central wavelength of $1030 \mathrm{~nm}$ (IR) was used. A third harmonic generation (THG) unit was applied to convert the central wavelength to $343 \mathrm{~nm}$ (UV), since in polymer films the absorption of laser energy at this wavelength is considerably higher than at $1030 \mathrm{~nm}$ and, for a lens with a given focal length, the focal spot diameter is smaller at $343 \mathrm{~nm}$ than at $1030 \mathrm{~nm}$. The beam showed a nearly Gaussian power density profile (beam quality $M^{2}<1.3$ ). The radiation was linearly polarized. To manipulate the beam over the sample, a two-mirror Galvano-scanner system (Intelliscan 14 , Scanlab GmbH, Germany) was used. The beam was focused to a diameter of about $10 \mu \mathrm{m}$ by a telecentric f $\theta$-lens (Ronar, Linos $\mathrm{GmbH}$, Germany) with a focal length of $100 \mathrm{~mm}$. All experiments were performed in a cleanroom facility. The $\sim 15 \mu \mathrm{m}$ thick thin polymer films were stretched on a custom-made Teflon sample holder to ensure a flat surface for laser processing. Holes with various diameters $(10 \mu \mathrm{m}, 20 \mu \mathrm{m}, 30 \mu \mathrm{m}$, and $40 \mu \mathrm{m}$ ) and spacings (50 $\mu \mathrm{m}, 100 \mu \mathrm{m}$, and $200 \mu \mathrm{m})$ were introduced into the polymer films by either percussion drilling or trepanning. A diameter of $10 \mu \mathrm{m}$ was obtained by percussion drilling using a pulse energy $\left(E_{p}\right)$ of $1 \mu \mathrm{J}$ and 150 pulses at a pulserepetition frequency $\left(\mathrm{F}_{\mathrm{pr}}\right)$ of $10 \mathrm{kHz}$. Trepanning with a pulse energy of $1 \mu \mathrm{J}$, a pulse-repetition frequency of $10 \mathrm{kHz}, 2$ iterations, and a beam velocity of $15 \mathrm{~mm} / \mathrm{s}$ was used to cut holes with larger diameters.

\subsection{Raman spectroscopy}

Raman spectroscopy was used to identify whether the laser processing induced chemical modifications of the polymer. For this, a laser processed film was mounted on a $\mathrm{CaF}_{2}$ slide (Crystran Ltd., Dorset, UK), immersed in Millipore water and covered with a cover slip. Raman measurements were performed using a custom-built confocal Raman spectrometer as described previously [18]. Briefly, a krypton ion laser (Inova 90-K; Coherent, Inc) emitting at $647.1 \mathrm{~nm}$ at a power of $15 \mathrm{~mW}$ under the objective was used as an excitation source. Raman spectra of the circumference of the holes were acquired in spectral scanning mode using a $40 \times / 0.75 \mathrm{NA}$ objective (Olympus UPFLN). Raman imaging was performed by raster-scanning the laser beam over an area of $20 \times 20 \mu \mathrm{m}$ with a step size of $1.25 \mu \mathrm{m}$ and an accumulation time of $0.5 \mathrm{~s} / \mathrm{step}$, while collecting a single spectrum at each step. All data manipulations were performed in routines written in MATLAB 7.6 (The MathWorks).

\subsection{In vitro cellular migration assay}

To demonstrate the potential of the porous construct for cell infiltration, an in vitro cell migration assay was performed with iMSCs, an immortalized human mesenchymal stromal cell line [19]. For this, HRE-GFP iMSCs [20] were seeded in a density of $3^{*} 10^{4}$ cells per $\mathrm{cm}^{2}$ on a layer of growth factor-reduced Matrigel (diluted 1:1 in medium; BD Biosciences, The Netherlands). After cell attachment, a porous microwell scaffold, fabricated by laser-drilling (pore spacing $200 \mu \mathrm{m}$ ), was placed on the cell layer and filled with growth factorreduced Matrigel. After $48 \mathrm{~h}$ of culture, the sample was carefully washed with PBS and immersed in 4\% paraformaldehyde in PBS for 30 min. Fixation was followed by two washing steps in PBS and a 30 min permeabilization step in $0.3 \%$ Triton-X 100/PBS. The sample was stained for F-Actin filaments with alexa-647-phalloidin (Invitrogen, USA, 1:40, $30 \mathrm{~min}$ ) and counterstained with DAPI (Invitrogen, USA, $1: 100,30 \mathrm{~min}$ ). Imaging was performed using an EVOS $^{\circledR}$ FL Imaging System (Invitrogen, USA).

\subsection{Nutrient diffusion through microwell scaffolds}

As an indicator for nutrient transport, the glucose diffusion through the porous microwell scaffolds was assessed as described previously $[15,21,22]$. Briefly, the setup consisted of two doublewalled compartments: a donor compartment filled with RPMI1640 (Invitrogen, USA) containing $11.1 \mathrm{mM}$ D-glucose, and an acceptor compartment containing RPMI-1640 without D-glucose (both compartments were supplemented with $100 \mathrm{U} / \mathrm{ml}$ penicillin and $10 \mu \mathrm{g} / \mathrm{ml}$ streptomycin (Invitrogen, USA)). The scaffolds were pre-wetted for several hours in RPMI-1640 (without D-glucose) and positioned between the two compartments. The temperature in the setup was maintained at $37^{\circ} \mathrm{C}$ with circulating water. At various time intervals, $80 \mu \mathrm{l}$ samples were obtained from both compartments and analyzed for glucose concentration using a Vitros DT60 II chemistry system (Ortho-Clinical Diagnostics, USA). The diffusion coefficient D across the scaffold can be calculated using the following equation, derived form Fick's first law of diffusion:

$D=\frac{V_{1} V_{2}}{V_{1}+V_{2}} \cdot \frac{L}{A} \cdot \frac{1}{t} \cdot \ln \frac{\left(C_{1}\right)_{0}}{\left(C_{1}\right)_{t}-\left(C_{2}\right)_{t}}$

Here, $\left(C_{1}\right)_{0}$ and $\left(C_{1}\right)_{t}$ are the initial and intermediary concentrations (at time $\mathrm{t}$ ) of the solute in the donor compartment, respectively; $\left(C_{2}\right)_{t}$ is the intermediary concentration (at time $t$ ) of the solution in the acceptor compartment; $V_{1}$ and $V_{2}$ are the volumes in the donor and acceptor compartments, respectively; $\mathrm{L}$ is the thickness of the scaffold; and $A$ is the diffusion area of the scaffold.

\subsection{Animals and induction of diabetes}

Fasted male BALB/c mice, 6 weeks old (Charles River Laboratories, Wilmington, MA, USA), were rendered diabetic with an intraperitoneal injection of $225 \mathrm{mg} / \mathrm{kg}$ streptozotocin (Sigma Aldrich, USA), freshly dissolved in citrate buffer ( $\mathrm{pH} 4.5$ ). Blood glucose levels were measured in whole blood obtained from the tail vein using a glucose meter (Accu-Chek, Roche Diagnostics, Switzerland). Only those mice exhibiting non-fasting blood glucose levels $>20 \mathrm{mM}$ for two consecutive days were considered diabetic and used as transplant recipients. Animal experiments were approved by the institutional ethical committee on animal care and experimentation at the Leiden University Medical Center.

\subsection{Islet isolation and scaffold seeding}

Islets were isolated from male BALB/c mice weighing $>28 \mathrm{~g}$. Donor mice were anesthetized with isoflurane. After a midline abdominal incision, the common bile duct was cannulated and perfused with $3 \mathrm{~mL}$ of $3 \mathrm{mg} / \mathrm{mL}$ collagenase type $\mathrm{V}$ (Sigma Aldrich, USA) in RPMI-1640 medium (Invitrogen, USA), supplemented with $2 \mu \mathrm{g} / \mathrm{mL}$ DNAse I (Pulmozyme, Roche, Switzerland). The pancreas was dissected and digested at $37{ }^{\circ} \mathrm{C}$ for $15 \mathrm{~min}$. Islets were handpicked and cultured overnight in islet medium (RPMI-1640 medium Invitrogen, USA), supplemented with $10 \%(\mathrm{v} / \mathrm{v})$ heatinactivated FCS (Bodinco, The Netherlands), penicillin/streptomycin $(100 \mathrm{U} / \mathrm{mL}$ and $10 \mu \mathrm{g} / \mathrm{mL}$, respectively, Invitrogen, USA), and $2 \mu \mathrm{g} / \mathrm{mL}$ DNAse I (Pulmozyme, Roche, Switzerland). An islet mass of 300 islets was seeded onto the porous microwell scaffolds in islet medium. After islet seeding, scaffolds were covered with a porous 4000 PEOT30PBT70 polymer film containing an array of $40 \mu \mathrm{m}$ holes, with a $200 \mu \mathrm{m}$ spacing. The porous cover was attached to the scaffold with three 6-0 silk sutures (Ethicon, UK). 


\subsection{Islet transplantation}

Prior to isoflurane anesthetics, mice were given $0.1 \mathrm{mg} / \mathrm{kg}$ buprenorfin (Temgesic, Schering-Plough, Belgium). For the scaffold and the non-scaffold control group, the epididymal fat was identified with a midline lower abdominal incision. Microwell scaffolds were inserted between the epididymal fat and peritoneum, with the lid of the construct facing the epididymal fat. For the nonscaffold group, the marginal islet mass of 300 islets was delivered in the epididymal fat using a Hamilton syringe (Hamilton, USA) and siliconized polyethylene tubing (PE50, Becton Dickinson, USA) with Sigmacote (Sigma Aldrich, Germany). A second control group included animals, according the gold standard, receiving 300 islets underneath the kidney capsule. For this, a small incision was made in the flank of the mouse which gave access to the kidney. Islets were injected underneath the kidney capsule using the Hamilton syringe and siliconized polyethylene tubing as described elsewhere [23]. After transplantation, the peritoneum and skin were closed and the animals were allowed to recover under a warm lamp. Blood glucose levels were measured in whole blood from the tail vein three times a week. Mice were considered normoglycemic when blood glucose levels were consistently less than $12 \mathrm{mM}$. Four weeks after transplantation, the mice were sacrificed and the grafts were retrieved for histological analysis. Two animals that received grafts underneath the kidney capsule underwent nephrectomy to confirm that normoglycemia after transplantation was graft dependent.

\subsection{Intraperitoneal glucose tolerance testing}

For metabolic assessment, intraperitoneal glucose tolerance tests (IPGTTs) were performed two and four weeks after transplantation. In overnight-fasted mice, blood glucose levels were measured before and 15, 30, 60, and 120 min after intraperitoneal injection of $2 \mathrm{~g} / \mathrm{kg}$ glucose solution.

\subsection{Tissue collection and immunohistochemistry}

Histological analyses were performed to compare the morphology and architecture of the transplanted islets compared to those of islets within pancreata from healthy mice. Grafts or pancreata from healthy control mice were immersed in $4 \%$ paraformaldehyde in PBS overnight at $4{ }^{\circ} \mathrm{C}$ and prepared for paraffin embedding. Each graft or pancreas was completely sectioned in 8$\mu \mathrm{m}$ slices. To identify islet-containing regions, sections spaced $160 \mu \mathrm{m}$ apart were stained for insulin combined with a MassonGoldner trichrome staining(Merck Chemicals, Darmstadt, Germany). Sections were immunostained with rabbit anti-insulin IgG (Santa Cruz Biotechnology, Santa Cruz, CA, USA, 1:400) for $1 \mathrm{~h}$ followed by an HRP-conjugated secondary antibody (DAKO, Glostrup, Denmark, 1:100) for $1 \mathrm{~h}$. Sections were developed with DAB liquid chromogen system (DAKO, Belgium) and counterstained with hematoxylin and Masson-Goldner trichrome staining according to manufacture's protocol. Slides were imaged using a Nanozoomer slide scanner 2.0 RS (Hamamatsu, Hamamatsu City, Japan).

Consecutive slides from two to three levels were randomly selected from islet-containing regions and immunostained for either insulin and glucagon, or insulin and CD31, to determine cellular composition and distribution, as well as the vascular density within the islets. Per islet transplant and control pancreas at least 30 islets were analyzed. Prior to staining, heat-mediated antigen retrieval (pressure cooker, $80{ }^{\circ} \mathrm{C}, 30 \mathrm{~min}$ ) was performed in sodium citrate buffer ( $\mathrm{pH}$ 6.0). For blocking normal goat serum, normal donkey serum, and a biotin/avidin blocking kit (Vector, USA) were applied. Primary antibodies used were guinea pig-anti- insulin (Abcam, Cambridge, MA, USA, 1:200, $1.5 \mathrm{~h}$ ), rabbit-antiglucagon (Vector Laboratories, Burlingame, CA, 1:100, o/n) and rabbit-anti-CD31 (Abcam, Cambridge, MA, USA, 1:20, o/n) were used. Secondary antibodies were Alexa-647-anti-guinea pig (Invitrogen Life Technologies, Paisley, UK, 1:500, 2 h), biotin-SPconjugated anti-rabbit (Jackson ImmunoResearch, West Grove, USA, 1:200, $1 \mathrm{~h}$ ), and Alexa-488-SA (Invitrogen Life Technologies, Paisley, UK, 1:200, 1 h). DAPI (Invitrogen Life Technologies, Paisley, UK) was applied as nuclear counterstaining. Sections were examined using a BD Pathway 435 system (BD BioSciences, San Jose, CA, USA) with a custom designed macro (Image software (http://rsb. info.nih.gov/ij/)).

\subsection{Morphometric analysis}

Custom-written ImageJ/Fiji (http://rsb.info.nih.gov/ij/) macros were used for morphometric analysis of histological parameters. To determine the vascular density per islet area, images were preprocessed by subtracting background signal and enhancing local contrast and converted to 8-bit images. The outline of the islets and vessels were semi-automatically delineated using several thresholding algorithms. The position of the blood vessel within the islets was determined by normalizing the distance between the center of the islet and the center of the blood vessel to the distance between the center of the islet and the boundary of the islet along the same radial vector. Thus, the position of the blood vessel was expressed as a value between 0 and 10 with 0 representing the center of the islet and 10 the boundary of the islet. Also for the characterization of cellular composition, images were pre-processed by subtracting background signal and enhancing local contrast and converted to 8bit images. The insulin and glucagon positive regions were semiautomatically delineated based on the individual images using several thresholding algorithms, whereas the outline of the islet was determined based on a merged image of both stainings. The DAPI image was segmented using Adjustable Watershed to obtain masks for individual cells. The insulin and glucagon selections were used to determine whether the cells were negative or positive for the hormones. As for the blood vessels, the position of the individual cells was represented by normalizing the distance between the center of the islet and the nuclei to the distance between the center of the islet and the boundary of the islet. Data were processed and analyzed using R [24], GraphPad Prism (La Jolla, CA, USA), and SPSS version 22 (SPSS, Chicago, IL, USA).

\subsection{Statistics}

Statistical analyses were performed using SPSS version 22 (SPSS, Chicago, IL, USA). P- values less than 0.05 were considered statistically significant. The results were presented as mean \pm standard error of the mean (SEM). Time to remission, defined as the number of days required to re-establish blood glucose levels consistently lower than $12 \mathrm{mM}$, was evaluated by Kaplan-Meier survival analysis with the log-rank test comparison. Group comparisons were performed using analysis of variance (ANOVA) with Holm's posthoc test after having assessed the assumptions of normality (Shapiro-Wilk test) and equality of variance (Levene test). If the assumption of normality was not validated, we used the KruskalWallis test and performed pairwise comparisons with the MannWhitney $U$ test in case the Kruskal-Wallis test indicated significant differences. If equality of variance was not present, significant differences in the measurement was determined by ANOVA and Games-Howell's test for multiple comparison of the means. Within-group comparisons of the IPGTT and the spatial distribution data of the histological analyses were made using a mixed-model ANOVA with Holm's post-hoc test. 


\section{Results}

\subsection{Comparison of different fabrication methods for porous} microwell scaffolds

Three different fabrication methods were compared to obtain both porous microwell scaffolds and porous lids with a maximum pore diameter of $40 \mu \mathrm{m}$. Methods were evaluated for pore size and geometry, reproducibility and flexibility, and the form and stability of the final construct. The first method consists of a solvent-casting and particulate leaching technique (Supplemental Fig. 1). After microthermoforming, sodium chloride crystals could clearly observed distributed throughout the microwell scaffold in a random manner (Fig. 1A). Crystals were efficiently removed (Fig. 1B) by dissolution as confirmed by EDX analysis (Supplemental Fig. 2), which resulted in porous constructs. The porosity could be controlled by increasing the salt-to-polymer ratio, resulting in a concomitant increase in the diffusion coefficient (Table 1). Although high porosities were obtained using this method, the average pore diameter was small $(18.3 \mu \mathrm{m})$ (Fig. 1C), and control over pore size and distribution was limited, as reflected by the large pore size distribution range $(5-65 \mu \mathrm{m})$. Furthermore, the shape of the microwells was irregular and rough, with a large variation throughout the entire construct.

The second technique used involved casting of the PEOT/PBT polymer solution on a patterned silicon wafer comprising small pillars (Supplemental Fig. 1, Supplemental Fig. 3). The method was optimized by varying the pillar diameter with a constant pillar spacing of $200 \mu \mathrm{m}$ (Supplemental Fig. 3). A minimum film thickness of $15 \mu \mathrm{m}$ was needed for stable microwell thermoforming, requiring a pillar height of $75 \mu \mathrm{m}$ to ensure this film was perforated during solvent evaporation. To achieve this height, the minimum pillar diameter that had sufficient mechanical properties was found to be $20 \mu \mathrm{m}$. This resulted in final pore sizes ranging from $20 \mu \mathrm{m}$ at the side of the microwells to $85 \mu \mathrm{m}$ at the rim, exceeding our stated upper limit of $40 \mu \mathrm{m}$ (Fig. 1F). Compared to particulate leaching, the pore geometry and spatial distribution were found to be very uniform (Fig. 1D-E). However, material properties of the mold and the associated pillar strength limited the minimum pore dimension that could be obtained.

The third method we investigated was laser drilling using an ultra-short pulsed laser source (Supplemental Fig. 1). The main advantage of this technique is its flexibility compared to the other techniques; the pore size can be easily adapted in a highly
PARTICULATE LEACHING

A

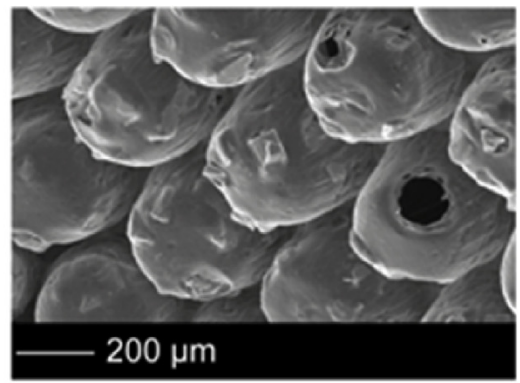

B

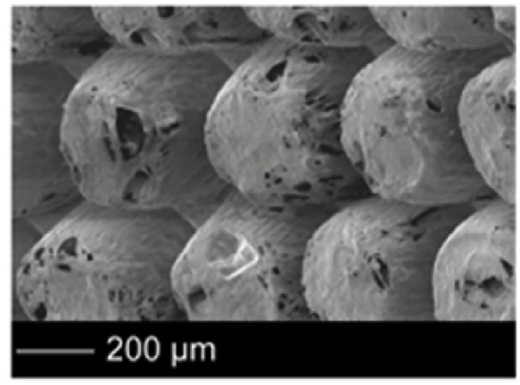

C

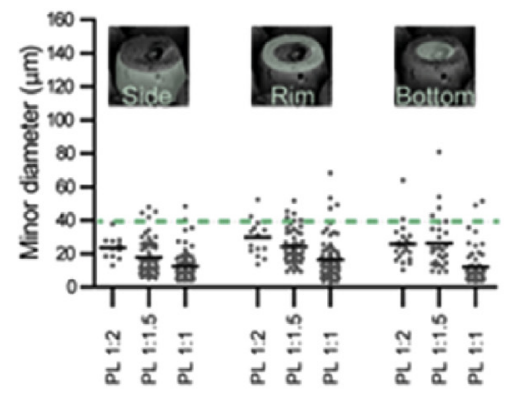

PILLARED WAFER

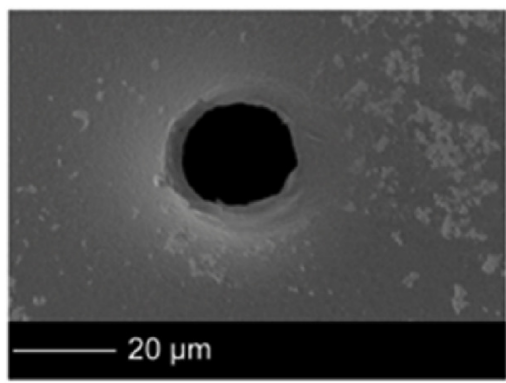

E

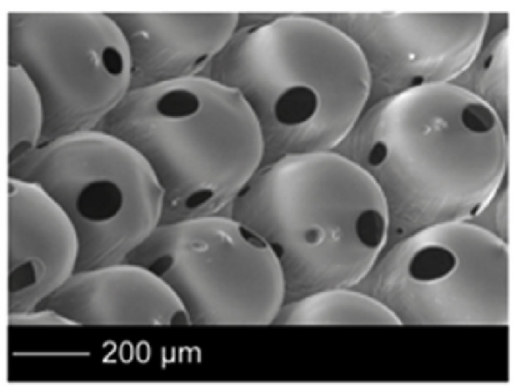

$\mathbf{F}$

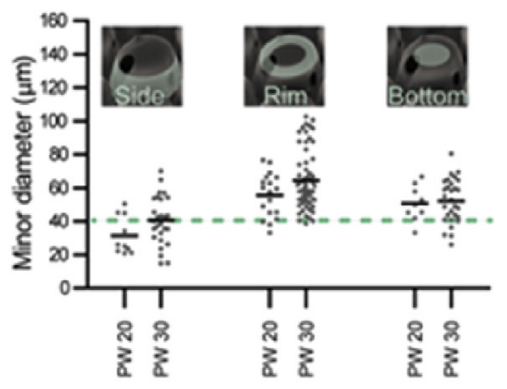

LASER DRILLING

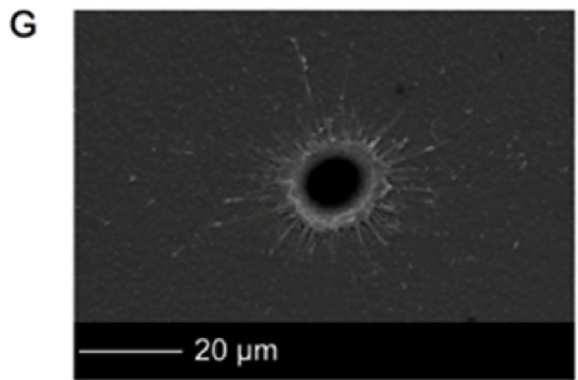

$\mathrm{H}$
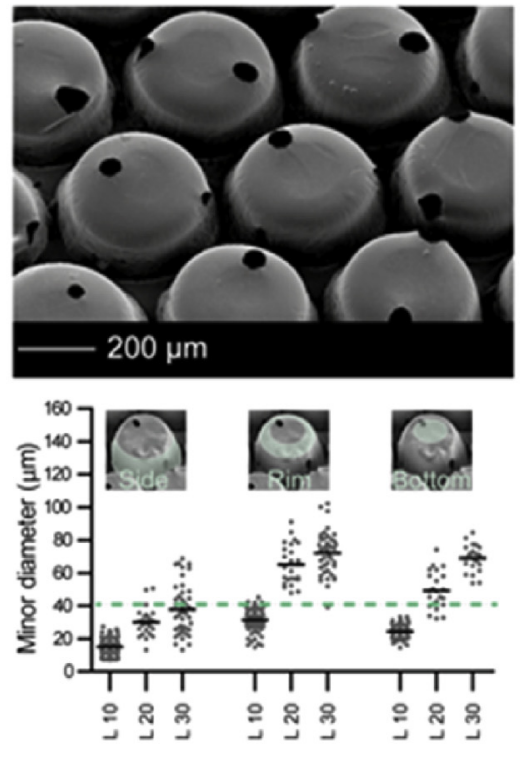

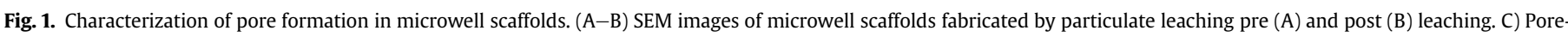

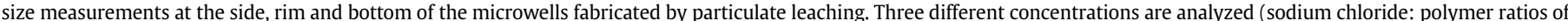

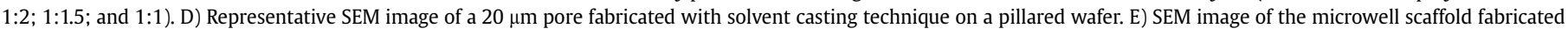

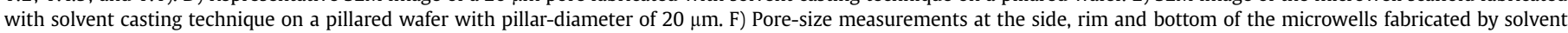

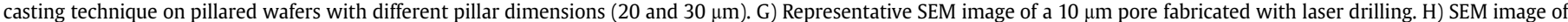

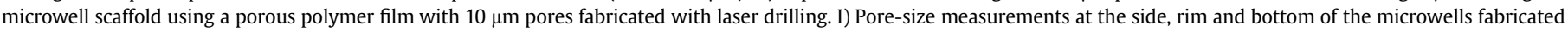
with laser drilling using polymer films with different pore diameters $(10,20,30 \mu \mathrm{m})$. 
Table 1

Diffusion coefficients of glucose through porous microwell scaffolds in medium at $37^{\circ} \mathrm{C}$

\begin{tabular}{|c|c|}
\hline Condition & Diffusion coefficient ${ }^{\mathrm{a}}\left(10^{-7} \mathrm{~cm}^{2} / \mathrm{s}\right)$ \\
\hline Particulate-leaching 1:2 & $5.5 \pm 0.4$ \\
\hline Particulate-leaching 1:1.5 & $11.8 \pm 1.5$ \\
\hline Particulate-leaching 1:1 & $32.4 \pm 7.2$ \\
\hline $\mathrm{PW} \varnothing 20 \mu \mathrm{m} \leftrightarrow 200 \mu \mathrm{m}$ & $4.8 \pm 0.2$ \\
\hline Laser $\varnothing 10 \mu \mathrm{m} \leftrightarrow 50 \mu \mathrm{m}$ & $20.0+2.4$ \\
\hline
\end{tabular}

a Free diffusion of glucose in medium at $37{ }^{\circ} \mathrm{C}$ is $92.5^{*} 10^{-7} \mathrm{~cm}^{2} / \mathrm{s}$ (Li Cancer 50(10), 2066, 1982).

reproducible and controllable manner, resulting in a very defined pore size distribution. After laser drilling, a small heat affected zone (HAZ) was observed around each pore (Fig. 1G-H). Spectroscopic analysis of the HAZ using a confocal Raman microscope found no significant differences between Raman spectra of the HAZ and unprocessed polymer film, indicating that the molecular composition of the polymer was not changed (Supplemental Fig. 4D). The smallest pore diameter that could be obtained with this technique was $10 \mu \mathrm{m}$, which resulted after microthermoforming in an average pore size below $40 \mu \mathrm{m}$, varying between $10 \mu \mathrm{m}$ at the side of the microwells and $40 \mu \mathrm{m}$ at the rim (Fig. 1I). By reducing the pore spacing, we found that the highest feasible pore density that did not adversely affect microwell morphology was an orthogonally stacked pore pattern with a spacing of $50 \mu \mathrm{m}$ (Fig. 2). This porosity resulted in a glucose diffusion coefficient of $20.0^{*} 10^{-7} \pm 2.4^{*} 10^{-7} \mathrm{~cm}^{2} / \mathrm{s}$, a four-fold increase compared to the glucose diffusion coefficient of pillared-wafer scaffolds and approaching the coefficient that could be obtained with the particulate leaching technique (Table 1 ).

Light-microscopy and SEM analysis of scaffold-seeded islets confirmed the laser pores were small enough to entrap islets in the microwells (Supplemental Figs. 5A-C). To analyse whether the porous structures allow cell infiltration, an in vitro migration assay was performed. For this, laser-drilled scaffolds were filled with Matrigel and placed on a layer of iMSCs seeded on Matrigel. Upon culturing hMSCs successfully penetrated and bridged the pores indicating its potential for cell infiltration (Supplemental Figs. 5D-E).

\subsection{Porous microwell scaffolds support extrahepatic islet transplantation}

To assess the potential of the laser-drilled porous microwell scaffold platform to assist extrahepatic islet engraftment, constructs were seeded with islets, covered with a flat porous thin-film lid with $40 \mu \mathrm{m}$ pores and transplanted into a diabetic mouse model for 28 days. When islets were transplanted in the scaffold, six out of eight animals (75\%) reverted to stable normoglycemia, with a mean time to remission of $6.2 \pm 3.2$ days (Fig. 3A-B). Although reversal time in the scaffold group was longer compared to the kidney control ( $2.2 \pm 0.83$ days) (Fig. $3 \mathrm{~A}-\mathrm{B})$, pairwise comparisons of the Kaplan-Meier curves indicated no significant difference between the two groups ( $p=0.093$ ) (Fig. 3D). In marked contrast, in the nonscaffold group $71 \%$ of the mice failed to restore blood glucose levels to normal values. The time to normoglycemia for the non-scaffold group was significantly longer compared to the kidney capsule control ( $p<0.01$ ) (Fig. 3A,C-D). Pairwise comparison with the scaffold group did not reveal a significant difference $(\mathrm{p}=0.068)$ (Fig. 3B-D). The body weight of all recipients increased following islet transplantation, indicating an overall improvement in the metabolic state (data not shown). In two mice with an islet transplant underneath the kidney capsule, a nephrectomy was performed. Both mice reverted to a state of hyperglycemia after graft removal, indicating that the islet grafts were responsible for sustaining normoglycemia (Fig. 3A).

The function of the islet grafts was examined further with intraperitoneal glucose tolerance tests (IPGTTs) two and four weeks post-transplantation (Fig. 3E-F). Baseline fasting glucose levels were similar between the groups. When islets where transplanted in the epididymal fat, either with or without a scaffold, glucose levels were elevated during IPGTT two weeks after transplantation, with a peak at 60 min compared to $15 \mathrm{~min}$ for renal subcapsular controls (Fig. 3E). Four weeks after implantation, the response of scaffold-implanted islets was improved reaching a peak at $30 \mathrm{~min}$, which was comparable to renal subcapsular islet grafts. However, when islets were implanted in the epididymal fat without a scaffold, glucose levels remained elevated following exogenous glucose administration, with a peak-value at $60 \mathrm{~min}$. Analysis of early $\left(\mathrm{AUC}_{(0-30 \mathrm{~min})}\right)$ and late-phase $\left(\mathrm{AUC}_{(30-120 \mathrm{~min})}\right)$ response showed no significant delay in response at both time points when islets were implanted in the scaffold compared to subcapsular control islets. This in contrast to islets transplanted in the epididymal fat without a scaffold (Fig. 3G-H).

\subsection{Porous microwell scaffolds allow vascular ingrowth}

Histological assessment showed viable islets within porous microwell scaffolds four weeks after transplantation (Fig. 4). Scaffolds were filled with granulation tissue and perfused vascular structures infiltrated the islet graft through the porous structure, indicating the formation of a functional vascular network within the islets (Fig. 4C). Unfortunately, we were unable to locate islet grafts for histological evaluation when islets were implanted in the epididymal fat without a scaffold. To assess vascular density and distribution, CD31 positive structures were identified within the islet grafts (Fig. 4D-F, Fig. 5A-C). Vascular density within renal subcapsular and scaffold-implanted islets was similar and comparable to native pancreatic islets (Fig. 5D). To assess the vessel distribution within the islet graft, the position of the blood vessel within the islets was determined by normalizing the distance between the center of the islet and the center of the blood vessel to the distance between the center of the islet and the boundary of the islet along the same radial vector. Thus, the position of the blood vessel was expressed as a value between 0 and 10 with 0 representing the center of the islet and 10 the boundary of the islet (Fig. 5E). The distribution of vessels within scaffold-implanted islets was found to be inhomogeneous, with a higher vascular density in the outer shell compared to the inner core $\left(1830 \pm 68\right.$ vessels $/ \mathrm{mm}^{2}$ 

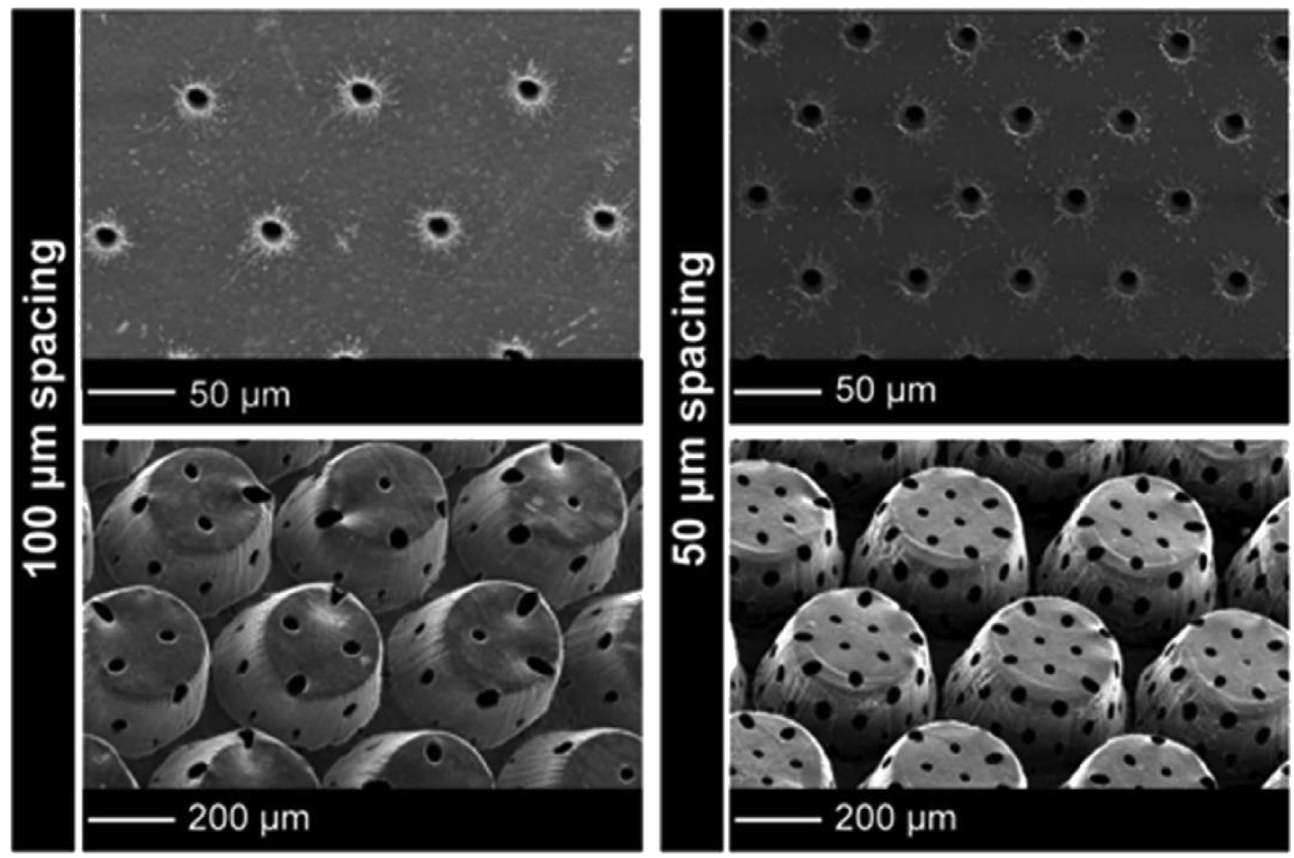

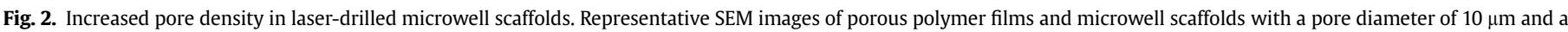
distance of $100 \mu \mathrm{m}$ (left panel) and $50 \mu \mathrm{m}$ (right panel).

vs. $924 \pm 87$ vessels $/ \mathrm{mm}^{2}$ ) (Fig. $5 \mathrm{~F}$ ). This is in contrast to subcapsular islet grafts that show a more homogeneous vessel distribution within the islets; a pattern similar to native pancreatic islets (Fig. 5F).

\subsection{Islet area and cellular composition}

To address whether islet area and composition changed after transplantation, the islet area and the density of both beta- and alpha-cells were determined (Fig. 6A-D). Islets transplanted in the microwell scaffold maintained their rounded morphology and islet size did not significantly differ from native islets (Fig. 6E and Supplemental Fig. 6). In contrast, islets transplanted underneath the kidney capsule showed some degree of aggregation and fusion increasing the islet size compared to pancreatic islets $(p<0.01)$ (Fig. 6E, Supplemental Fig. 6). Although the morphology of scaffoldimplanted islets was maintained, cellular density within the islets was significantly decreased compared to native islets (pancreas $10251.5 \pm 328.0$ cells $/ \mathrm{mm}^{2}$ vs. scaffold $8630.5 \pm 211.9$ cells $/ \mathrm{mm}^{2}$, $\mathrm{p}<0.01$ ) (Fig. 6F), with the most pronounced decrease in the core of the islets (Fig. 6H). This decrease was mainly attributed to a reduction in beta-cells (pancreas $6531.4 \pm 87.5$ cells $/ \mathrm{mm}^{2}$ vs. scaffold $4107.2 \pm 116.5$ cells $\left./ \mathrm{mm}^{2}, \mathrm{p}<0.001\right)$, whereas the alpha-cell density slightly, but not significantly, increased (Fig. 6G). Although renal subcapsular islet grafts exhibited a higher beta-cell density compared to scaffold-implanted islets (kidney capsule $5324.6 \pm 365.6$ vs. scaffold $1382.4 \pm 101.9, \mathrm{p}<0.01)$, this density was significantly lower compared to native islets (pancreas $6531.4 \pm 87.5$ cells $/ \mathrm{mm}^{2}$ vs. kidney capsule $5324.6 \pm 365.6$ cells/ $\mathrm{mm}^{2}, \mathrm{p}<0.05$ ) (Fig. 6G).

A distinct core-mantle structure was found in native islets, reflected by a higher alpha-cell density in the islet's outer shell compared to the central core (shell $2168.0 \pm 454.6$ cells $/ \mathrm{mm}^{2}$ vs. core $319.3 \pm 108.5$ cells $/ \mathrm{mm}^{2}$ ) (Fig. $6 \mathrm{H}$ ); characteristic for rodent islets [25]. Remarkably, this core-mantle structure was disrupted in both the scaffold-implanted and renal subcapsular islet grafts, presenting a more homogeneous distribution of alpha-cells throughout the islets and a reduction in the beta-cell density (Fig. 6H).

\section{Discussion}

This study shows that with our microwell scaffold platform extrahepatic islet transplantation becomes a viable option. In a diabetic mouse model, we achieved glycemic control that approaches the gold standard of renal subcapsular islet grafts after four weeks of engraftment. The microwell structure prevents islet aggregation, ensuring maintenance of the native rounded morphology and islet size. Meanwhile, the highly controlled pore size and pore distribution not only guarantees islet retention in the construct, but also allows mass transfer of metabolites and ingrowth of blood vessels, resulting in an intra-islet vascular density that is comparable to native islets.

Creating microwells with an appropriate size and distribution allows us to sequester and retain islets while limiting islet aggregation and fusion. When islets are cultured or transplanted in high density without physical separation, islets fuse in large clusters [26]; this is observed for islets implanted underneath the kidney capsule (Fig. 5B). As an increase in islet size is associated with more abundant apoptosis and necrosis [27-29] and with compromised in vivo performance $[28,29]$, this is desirable to avoid. Previously reported porous sponges designed for islet transplantation can prevent mass fusion to some degree, but these constructs have poor control over islet spacing, distribution and density [30-38] and can still enable islets to aggregate and coalesce. The unique aspect of microthermoforming is that it enables the reproducible creation of microwell structures with a designed shape, size, and distribution that not only limit islet aggregation, but also recreate the islet density found in human pancreatic tissue $[39,40]$.

As the renal subcapsular site is the gold standard for islet transplantation in pre-clinical mouse models, we selected this site as our control. This site offers the advantage of a confined environment for islet retention and engraftment, and in rodents, islets transplanted at this site outperform intrahepatic islet grafts [41]. 
A

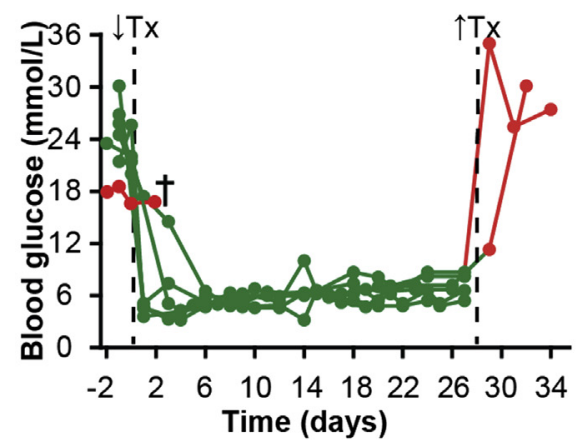

D

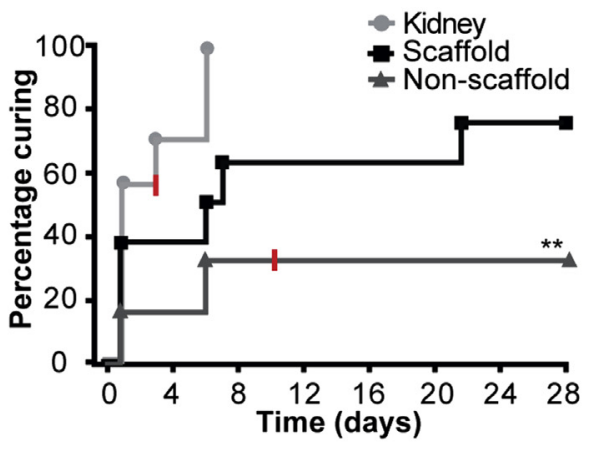

G

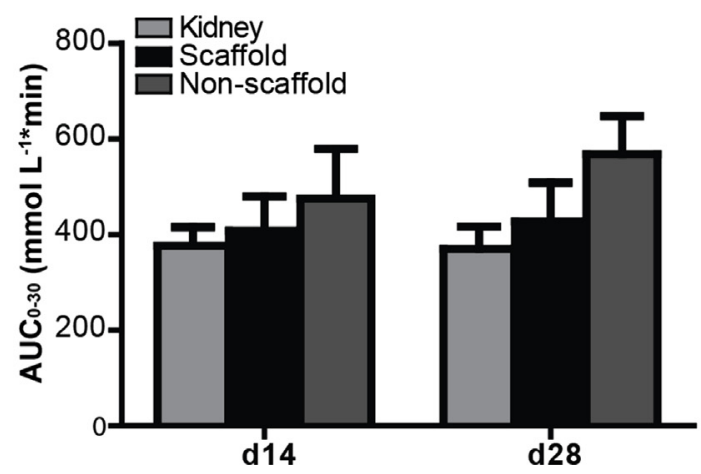

B

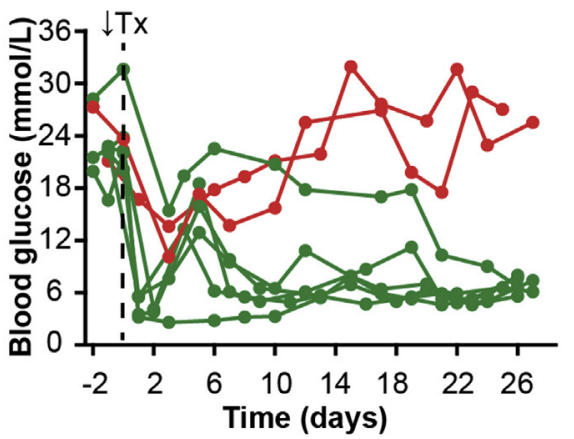

$\mathrm{E}$

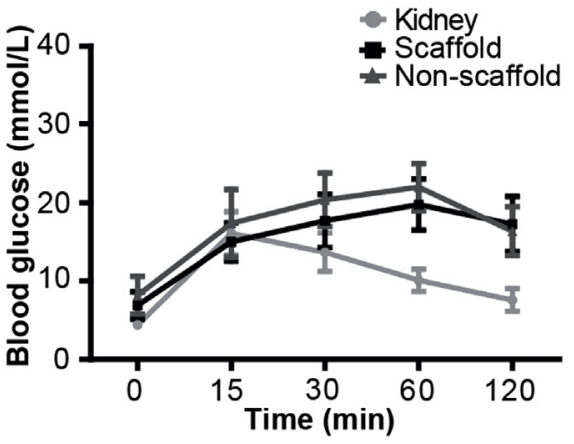

C

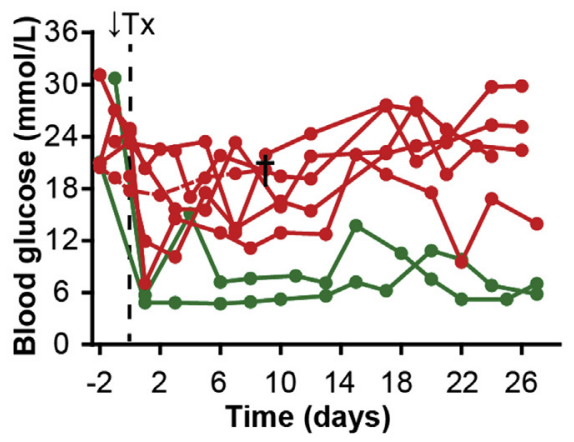

$\mathrm{F}$

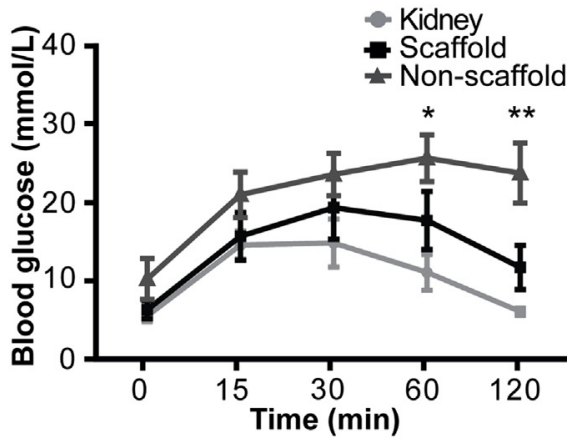

$\mathrm{H}$

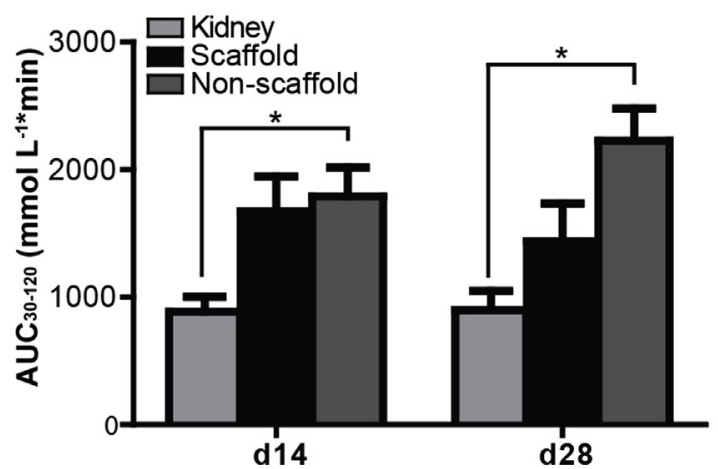

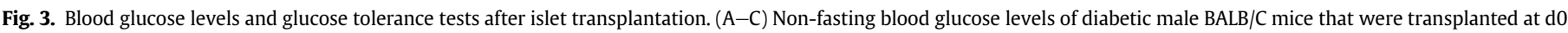

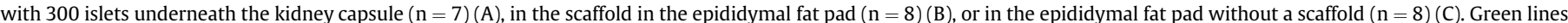

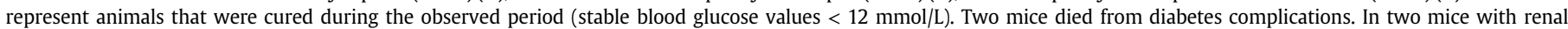

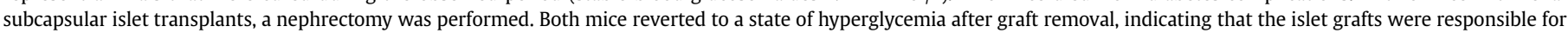

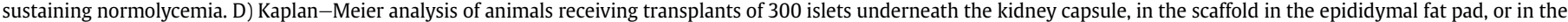

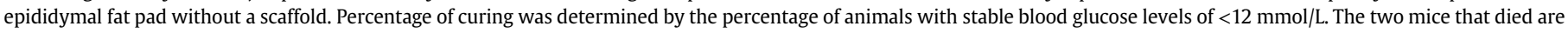

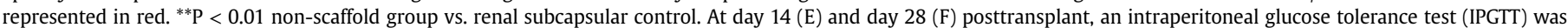

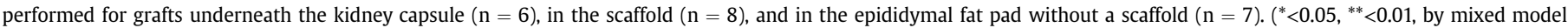

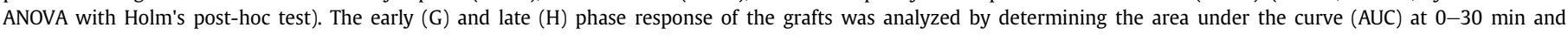

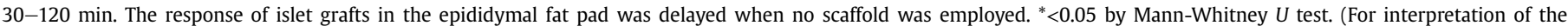
references to colour in this figure legend, the reader is referred to the web version of this article.)

However, this site is not attractive from a clinical perspective. Apart from the difficult access and the presence of diabetic nephropathy in a large proportion of the recipients, the performance of renal subcapsular islet grafts in humans is worse compared to intraportal islet grafts [42]. Many other clinically relevant sites currently considered, such as the omentum [38,43] and the intraperitoneal fat [36], are unable to appropriately confine islets. At these sites, better glycemic control can be achieved in diabetic animals when scaffolds are used to spatially stabilize the islets. Success of these implants, however, largely depends on the degree of islet retention and the efficiency of islet revascularization [44]. Previous scaffold designs attempted to achieve high rates of vascularization by providing large pores, varying from $\sim 250$ to $600 \mu \mathrm{m}$, open for tissue infiltration. However, since islet themselves have diameters ranging from $\sim 50$ to $400 \mu \mathrm{m}$ [45], these scaffolds are intrinsically prone to islet loss; this has been specifically reported for islets smaller than $100 \mu \mathrm{m}$ in diameter [38], a typical size for human islet preparations [45]. To improve islet retention, hydrogels have been used as a seeding matrix in concert with large-pored solid scaffolds $[30,37,46]$. Although hydrogels are able to sustain islet retention and prevent islet aggregation, vessel invasion is often limited by the rate of cell-mediated degradation due to the small mesh size of the crosslinked network $[47,48]$.

Our islet carrier platform is the first to employ a pore size that 


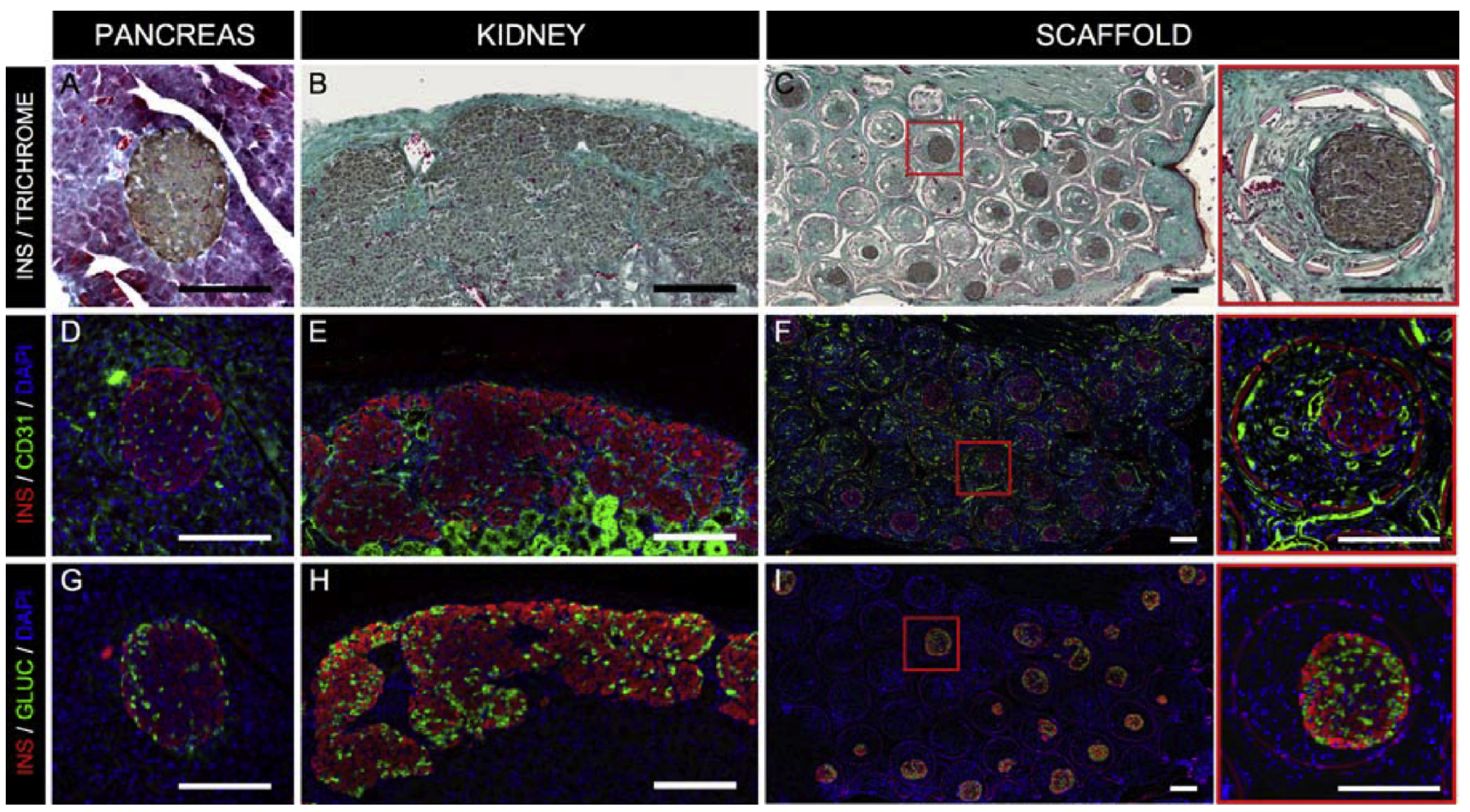

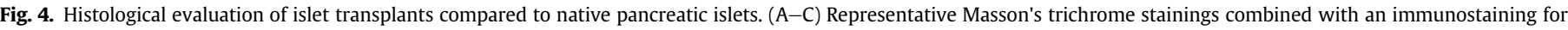

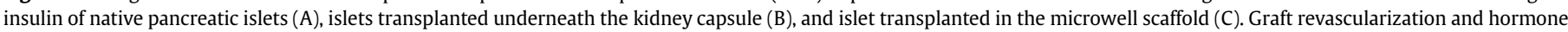

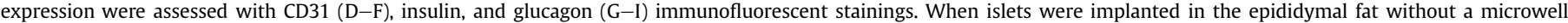
scaffold, islet grafts could not be retrieved successfully, likely due to islet migration or loss. Scale bars are $200 \mu \mathrm{m}$.

ranges from 10 to $40 \mu \mathrm{m}$, stimulating nutrient diffusion and vascular ingrowth through these well-defined pores while still providing high retention of islets. Not only has pore dimension been shown to promote vascularization by passively permitting cell infiltration, but it can also play an active role in the stimulation of vascularized tissue formation [14]. Interestingly, implants with 30-40 $\mu \mathrm{m}$ pores elicit a response with minimal fibrous encapsulation and maximal vascularization compared to constructs with smaller or larger pores [14]. Although the exact mechanisms, which underlie this observed response, remain largely unknown, it is hypothesized that pore size influences macrophage polarity initiating the transition from M1 to M2 phenotype and, by this, promotes constructive tissue remodeling [49]. Specific to our platform, the laser drilling method for pore fabrication is amenable to further optimization of pore size and distribution and holds great potential for developing a construct that can tune the host tissue response to maximize vascularization and subsequent islet engraftment.

In this study, we demonstrate that the microwell scaffold makes the epididymal fat a viable option for islet transplantation, with performance that is approaching the gold standard after four weeks of engraftment, in contrast to the poor outcome transplanting islet in the epididymal fat without the scaffold platform. The epididymal fat pad was selected as the site of implantation due to its surgical accessibility, vascularization, and structural similarity to the greater omentum, a potential extrahepatic transplantation site in humans [50]. Consistent with previous studies [30,37], we demonstrate that scaffolds are beneficial for islet graft performance in the epididymal fat. Since we were unable to locate islet grafts when islets were implanted in the epididymal fat without a scaffold, we speculate that the improvement in graft performance is due to immobilization of the islets. Furthermore, with our porous microwell scaffold platform, we obtain similar functional results using significantly fewer islets in comparison to the only other report on scaffoldaided islet transplantation in the epididymal fat of BALB/C mice [30], further highlighting the effectiveness of our strategy.

To the best of our knowledge, we are the first to directly compare the intra-islet vascular and cellular density and distribution of native pancreatic islets to both scaffold-engrafted islets and renal subcapsular-transplanted islets. We have shown that islets in our scaffold achieve a vascular density similar to subcapsular grafts and native pancreatic islets, although we observe differences in vascular distribution. Blood vessels in scaffold-implanted islets are preferentially located in the islet periphery while a homogeneous distribution is observed in both renal-transplanted and native islets. Corresponding to this vascularization pattern, we observe a decrease in cellular density in the islet core, possibly indicating hypoxia-induced cell death. We have shown that the diffusion coefficient of the scaffold $\left(20.0^{*} 10^{-7} \pm 2.4^{*} 10^{-7} \mathrm{~cm}^{2} / \mathrm{s}\right)$ is comparable to that of fibrous tissue such as dura mater $\left(\sim 25.9^{*} 10^{-7} \mathrm{~cm}^{2} / \mathrm{s}\right)[51]$ and human sclera $\left(\sim 34.5^{*} 10^{-7} \mathrm{~cm}^{2} / \mathrm{s}\right)$ [52], but the scaffold likely imposes an additional barrier for vascular ingrowth which would expose islets to an avascular, hypoxic environment for a longer period of time. Although hypoxia enhances VEGF expression and secretion from islet cells [53], thereby inducing revascularization, prolonged hypoxic exposure has been shown to result in central core necrosis [27]. This cell loss would translate to a decrease in VEGF production in the islet core, reinforcing a superficial revascularization pattern. Supporting this hypothesis is a report on similar changes in vascularization observed in Rip-Cre; VEGF $F^{\mathrm{f} / \mathrm{fl}}$ islets, where VEGF-A expression occurs only in the islet perimeter [54]. Therefore, we speculate that the observed change in vascularization pattern is a result of oxygen-gradient dependent cell death and a concomitant reduction in expression of proangiogenic factors, such as VEGF, due to delayed engraftment. 

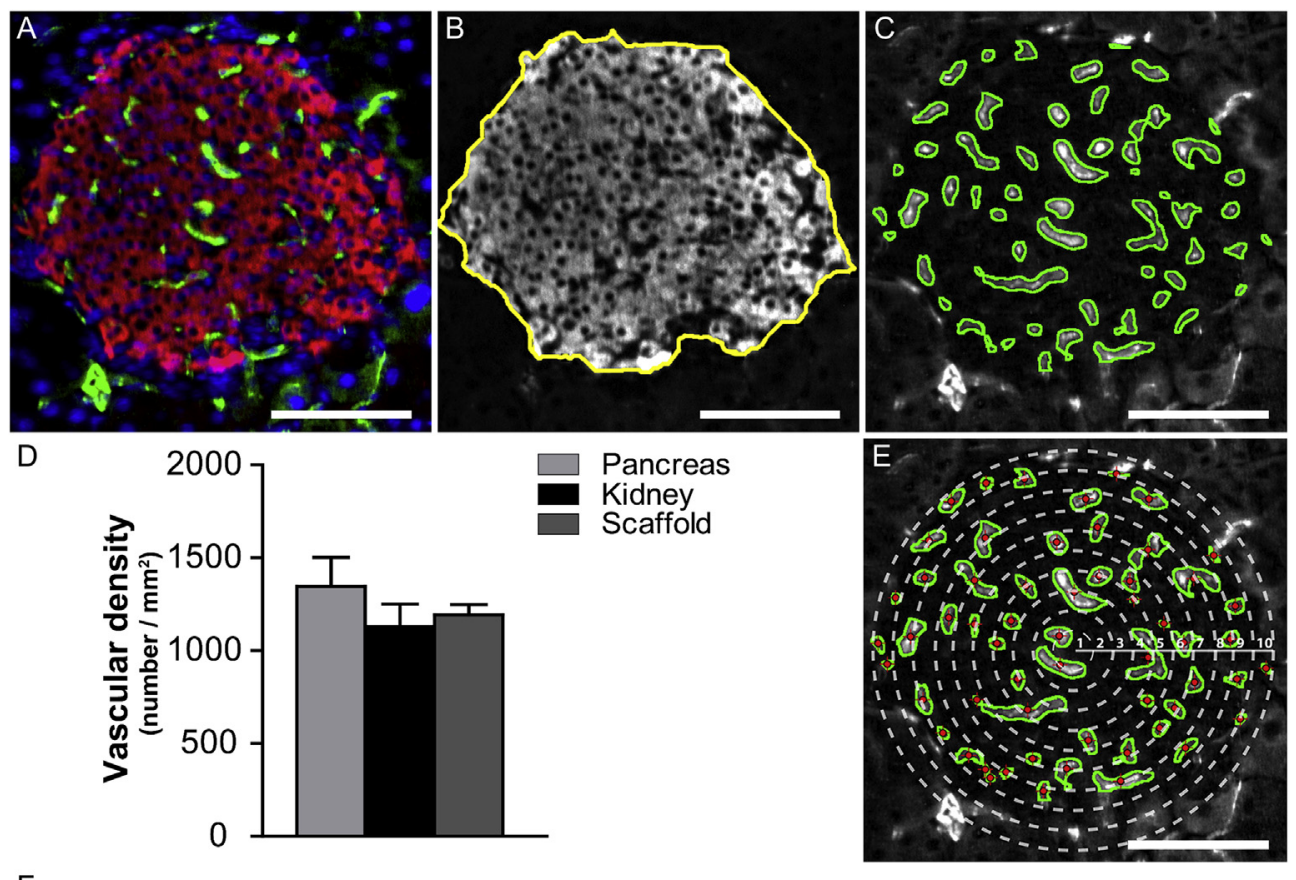

$\mathrm{F}$

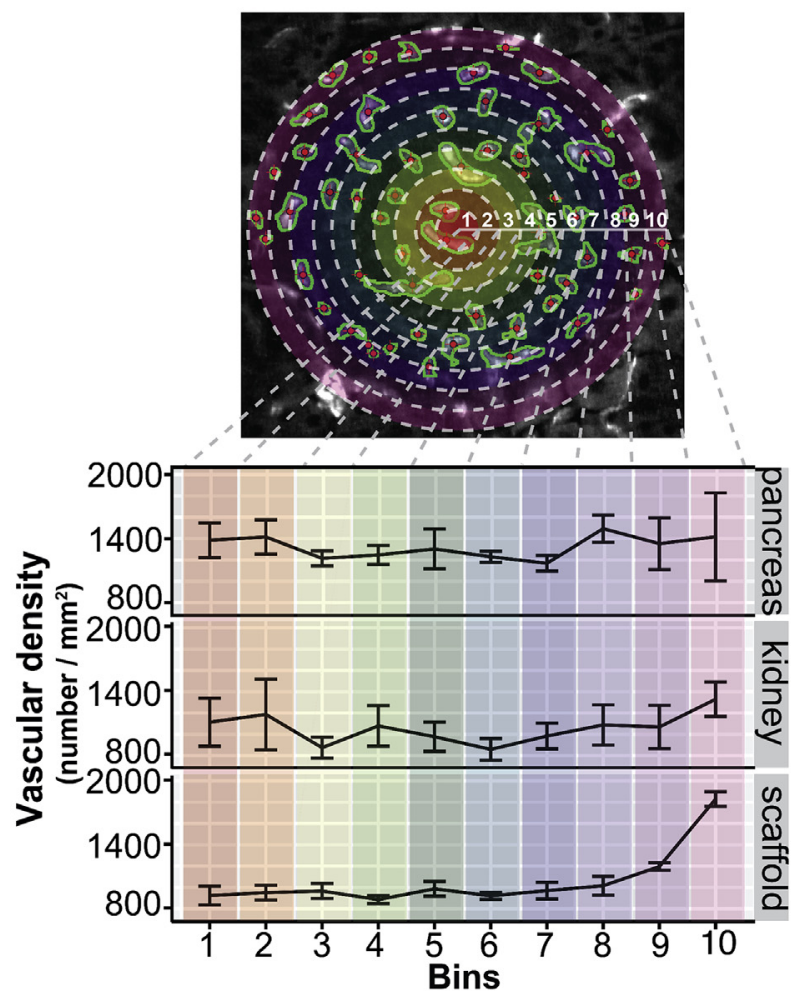

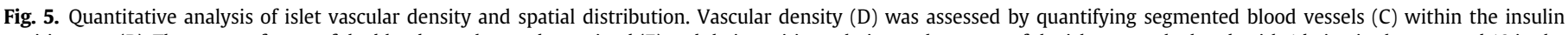

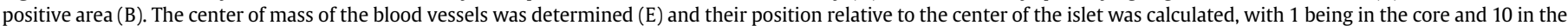
outer shell (F) to provide the vascular spatial distribution within the islet. Scale bars are $100 \mu \mathrm{m}$.

Islets transplanted within our scaffold platform are able to maintain a viable beta-cell population and, as a result, restore systemic glycemic control. However, we do observe a significant decrease in the beta-cell population after islet transplantation. The finding of a preferential decrease in beta-cell density compared to alpha-cell density might be attributed to a combination of the coremantle structure of rodent islets, with beta-cells in the core and alpha-cells in the periphery [55], and the higher susceptibility of beta-cells to hypoxia compared to alpha-cells [56]. Interestingly, we also detect more glucagon positive cells within the core of transplanted islets compared to native pancreatic islets. Possible explanations for this observation could be cellular rearrangement after cell death in the inner core or a reduced expression of cell adhesion molecules, such as N-CAM; heterozygote and null mutant mice for NCAM show infiltrating alpha-cells into the islet core [57]. Alternatively, the conversion of beta-cells into alpha-cells could 

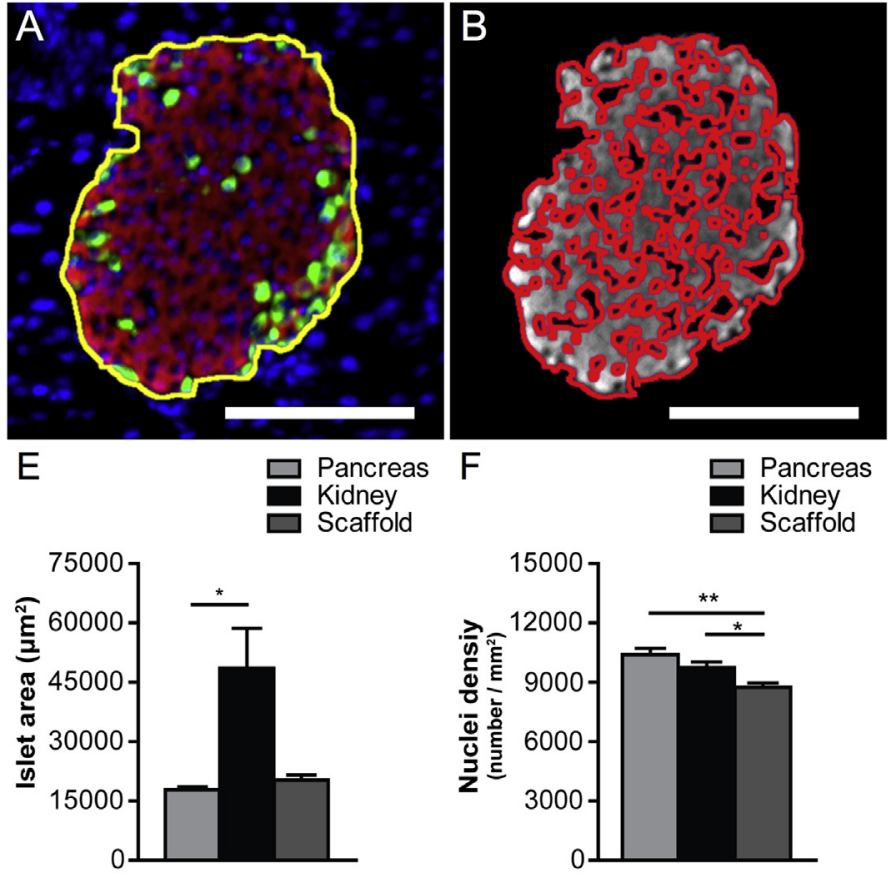

G

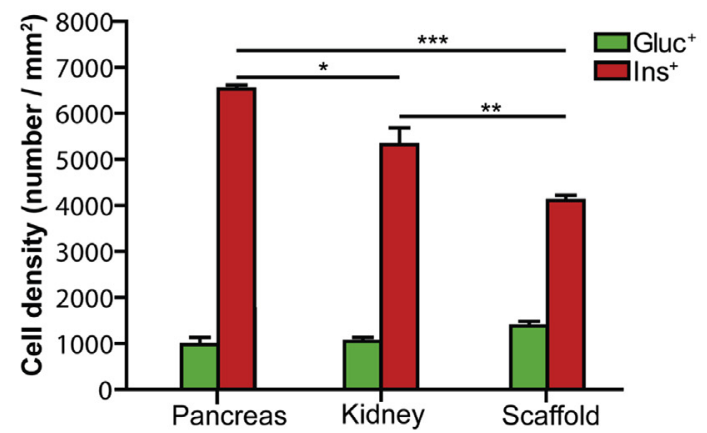

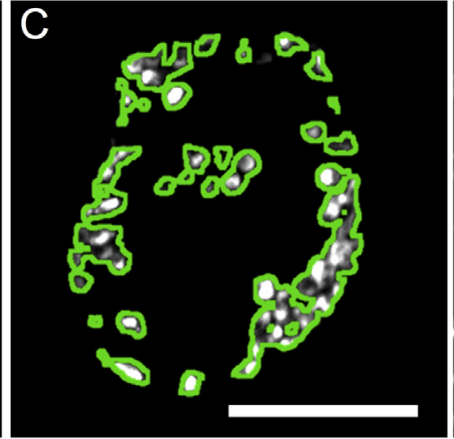

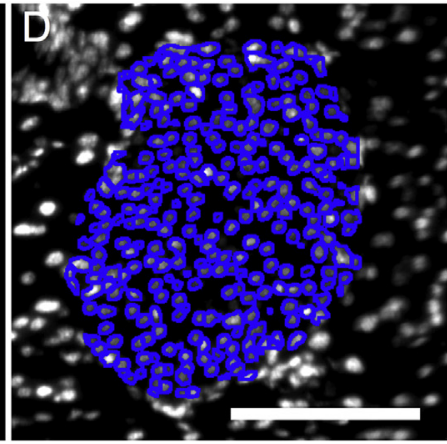

$\mathrm{H}$

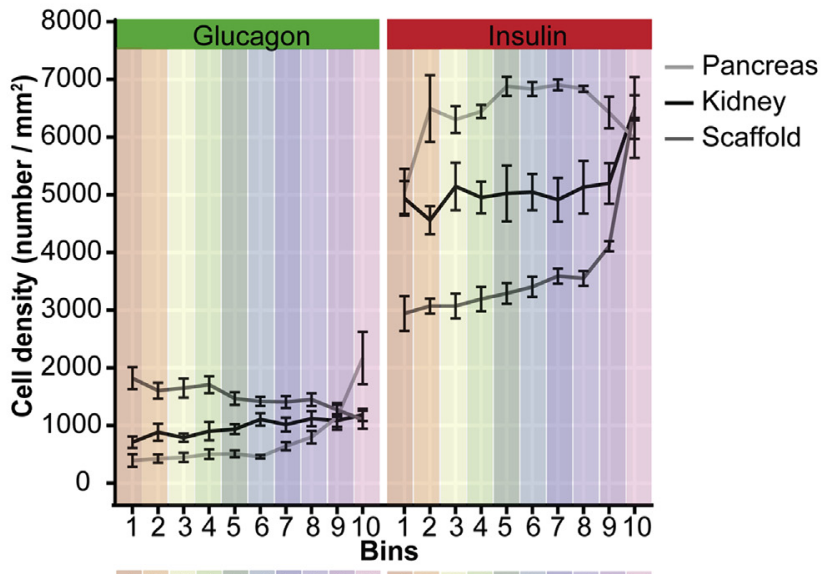

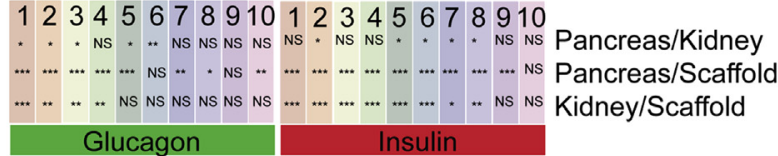

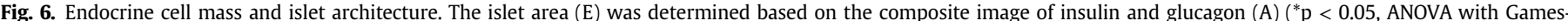

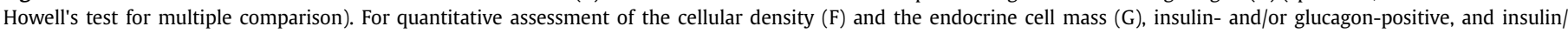

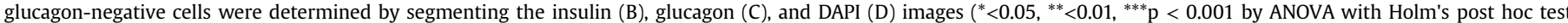

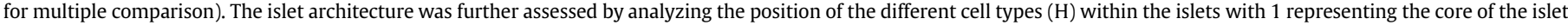
and 10 the outer shell. $\left({ }^{*}<0.05,{ }^{* *}<0.01,{ }^{* * *} \mathrm{p}<0,001\right.$ by mixed model ANOVA with Holm's post-hoc test for multiple comparison). Scale bars are $100 \mu \mathrm{m}$.

explain the increased presence of alpha cells in the islet core. Betacell to alpha-cell conversion has recently been shown to occur after beta-cell degranulation [58] and is associated with hyperglycemic and oxidative stress $[59,60]$. Further research is necessary to identify the underlying cause of this observation and the implications it has for islet functionality.

The current study presents a microwell scaffold as a suitable carrier for islets at extrahepatic sites, providing a promising alternative to intrahepatic transplantation. The approach of thermoformed microwells fabrication combined with laser-drilled micropores results in a highly flexibly and tunable platform. Possible avenues for further optimization should focus on approaches which allay hypoxia during the early engraftment period, such as the use of oxygen-generating biomaterials [61] or the incorporation of ECM molecules $[34,35,62]$ or growth factors $[37,46]$ within the scaffold to expedite vascularization. A simple means of optimization, intrinsic to this system, is the further tuning of micropore size and distribution so as to elicit a predominant M2 macrophage phenotype. Not only will this result in an optimal loose fibrous capsule for fast and effective vessel infiltration [14], but also promote beta-cell regeneration [63]. Furthermore, to assist in the translation of this approach towards the clinic, long-term experiments in a type 1 diabetes animal model under autogenic and allogenic settings are still required. As the current study has shown, the microwell scaffold platform facilitates detailed analysis at a subcellular level to substantiate functional physiological observations. This makes the microwell scaffold not only a potential platform for extrahepatic islet transplantation, but also a suitable candidate to thoroughly study the effect of different strategies on islet function and survival during the early engraftment period.

\section{Acknowledgements}

This project was financially supported by the Diabetes Cell Therapy Initiative (DCTI) FES 2009 program LSH-DCTI including the Dutch Diabetes Research Foundation (DF). The authors thank H.A.M Töns and dr. J.H. Ellenbroek from the department of Nephrology (Leiden University Medical Center, Leiden, The Netherlands) for their assistance in islet isolation and handpicking, Ing. G.H.P. Ebberink from the department of Mechanical Automation (University of Twente, Enschede, The Netherlands) for his technical assistance in laser drilling, $Z$. Tahmasebi Birgani from the 
department of Tissue Regeration (University of Twente, Enschede, The Netherlands) for her technical support with the EDAX analysis, Prof.dr. D. Stamatialis, department of Biomaterials Science and Technology (University of Twente, Enschede, The Netherlands) for his scientific support regarding the glucose diffusion experiments, Prof.dr. J. van der Palen, Department of Research Methodology, Measurement and Data Analysis, Faculty of Behavioral Science (University of Twente, Enschede, The Netherlands), and dr. T. de Haan, Department for Health Evidence (RadboudUMC, Nijmegen, The Netherlands) for their assistance regarding the statistical analysis of the data.

\section{Appendix A. Supplementary data}

Supplementary data related to this article can be found at http:// dx.doi.org/10.1016/j.biomaterials.2017.03.031.

\section{References}

[1] A.M. Shapiro, et al., International trial of the Edmonton protocol for islet transplantation, N. Engl. J. Med. 355 (2006) 1318-1330.

[2] F.B. Barton, et al., Improvement in outcomes of clinical islet transplantation: 1999-2010, Diabetes Care 35 (2012) 1436-1445.

[3] L. Moberg, et al., Production of tissue factor by pancreatic islet cells as a trigger of detrimental thrombotic reactions in clinical islet transplantation, Lancet 360 (2002) 11-13.

[4] B. Nilsson, K.N. Ekdahl, O. Korsgren, Control of instant blood-mediated inflammatory reaction to improve islets of Langerhans engraftment, Curr. Opin. Organ Transpl. 16 (2011) 620-626.

[5] P. Carlsson, F. Palm, A. Andersson, P. Liss, Markedly Decreased Oxygen Tension in Transplanted Site sure of oxygen ( P O 2 ) levels of these transplanted islets, Diabetes 50 (2001)

[6] R. Olsson, J. Olerud, U. Pettersson, P.-O. Carlsson, Increased numbers of lowoxygenated pancreatic islets after intraportal islet transplantation, Diabetes 60 (2011) 2350-2353.

[7] N.M. Desai, et al., Elevated portal vein drug levels of sirolimus and tacrolimus in islet transplant recipients: local immunosuppression or islet toxicity? Transplantation 76 (2003) 1623-1625.

[8] E. Cantarelli, L. Piemonti, Alternative transplantation sites for pancreatic islet grafts, Curr. Diab Rep. 11 (2011) 364-374.

[9] D.J. Borg, E. Bonifacio, The use of biomaterials in islet transplantation, Curr. Diab Rep. 11 (2011) 434-444.

[10] L.D. Amer, M.J. Mahoney, S.J. Bryant, Tissue Engineering Approaches to Cellbased Type 1 Diabetes Therapy, 1,2. 20:1-13, 2014.

[11] M. Salvatori, et al., Extracellular matrix scaffold Technology for bioartificial pancreas engineering: state of the art and future challenges, J. Diabetes Sci. Technol. 8 (2014) 159-169.

[12] O.C. Richards, S.M. Raines, A.D. Attie, The role of blood vessels, endothelial cells, and vascular pericytes in insulin secretion and peripheral insulin action, Endocr. Rev. 31 (2010) 343-363.

[13] E. Lammert, et al., Role of VEGF-a in vascularization of pancreatic islets, Curr. Biol. 13 (2003) 1070-1074.

[14] L.R. Madden, et al., Proangiogenic scaffolds as functional templates for cardiac tissue engineering, Proc. Natl. Acad. Sci. U. S. A. 107 (2010) 15211-15216.

[15] M. Buitinga, et al., Microwell scaffolds for the extrahepatic transplantation of islets of langerhans, PLoS One 8 (2013) e64772.

[16] S. Giselbrecht, et al., 3D tissue culture substrates produced by microthermoforming of pre-processed polymer films, Biomed. Microdevices 8 (2006) 191-199.

[17] R. Truckenmuller, et al., Thermoforming of film-based biomedical microdevices, Adv. Mater 23 (2011) 1311-1329.

[18] J. Hilderink, et al., Label-free detection of insulin and glucagon within human islets of Langerhans using Raman spectroscopy, PLoS One 8 (2013) e78148.

[19] M. Skårn, et al., Generation and characterization of an immortalized human mesenchymal stromal cell line, Stem Cells Dev. 23 (2014) 2377-2389,

[20] J. Doorn, et al., A small molecule approach to engineering vascularized tissue, Biomaterials 34 (2013) 3053-3063.

[21] B.J. Papenburg, et al., One-step fabrication of porous micropatterned scaffolds to control cell behavior, Biomaterials 28 (2007) 1998-2009.

[22] L.-Y. Chu, T. Niitsuma, T. Yamaguchi, S. Nakao, Thermoresponsive transport through porous membranes with grafted PNIPAM gates, AIChE J. 49 (2003) 896-909.

[23] G.L. Szot, P. Koudria, J.A. Bluestone, Transplantation of pancreatic islets into the kidney capsule of diabetic mice, J. Vis. Exp. 404 (2007).

[24] R Core Team, R: a Language and Environment for Statistical Computing, R Foundation for Statistical Computing, 2013.

[25] M. Brissova, et al., Assessment of human pancreatic islet architecture and composition by laser scanning confocal microscopy, J. Histochem Cytochem 53 (2005) 1087-1097.
[26] A.M. Davalli, et al., Vulnerability of Islets in the Immediate Posttransplantation Period, 19, 1996, pp. 1161-1167.

[27] M. Giuliani, et al., Central necrosis in isolated hypoxic human pancreatic islets: evidence for postisolation ischemia, Cell Transpl. 14 (2005) 67-76.

[28] R. Lehmann, et al., Superiority of small islets in human islet transplantation, Diabetes 56 (2007) 594-603.

[29] R.R. Macgregor, S.J. Williams, P.Y. Tong, K. Kover, W.V. Moore, Small Rat Islets are Superior to Large Islets in in Vitro Function and in Transplantation Outcomes, vol. 66160, 2006, pp. 771-779.

[30] J.M. Dufour, et al., Development of an ectopic site for islet transplantation, using biodegradable scaffolds, Tissue Eng. 11 (2005) 1323-1331.

[31] D.M. Salvay, et al., Extracellular matrix protein-coated scaffolds promote the reversal of diabetes after extrahepatic islet transplantation david, Transplantation 85 (2009) 1456-1464.

[32] T. Kheradmand, et al., Permanent protection of PLG scaffold transplanted allogeneic islet grafts in diabetic mice treated with ECDI-fixed donor splenocyte infusions, Biomaterials 32 (2011) 4517-4524.

[33] R.F. Gibly, et al., Extrahepatic islet transplantation with microporous polymer scaffolds in syngeneic mouse and allogeneic porcine models, Biomaterials 32 (2011) 9677-9684.

[34] R.F. Gibly, X. Zhang, W.L. Lowe, L.D. Shea, Porous scaffolds support extrahepatic human islet transplantation, engraftment, and function in mice, Cell Transpl. 22 (2013) 811-819.

[35] W.T. Yap, et al., Collagen IV-modified Scaffolds Improve Islet Survival and Function and Reduce Time to Euglycemia, vol. 19, 2013.

[36] H. Blomeier, et al., Polymer scaffolds as synthetic microenvironments for extrahepatic islet transplantation, Transplantation 82 (2006) 452-459.

[37] A.-C. Brady, et al., Proangiogenic Hydrogels within Macroporous Scaffolds Enhance Islet Engraftment in an Extrahepatic Site, vol. 19, 2013, pp. $2544-2552$.

[38] E. Pedraza, et al., Macroporous three-dimensional pdms scaffolds for extrahepatic islet transplantation, Cell Transpl. 22 (2013) 1123-1135.

[39] J.J. Meier, et al., Beta-cell replication is the primary mechanism subserving the postnatal expansion of beta-cell mass in humans, Diabetes 57 (2008) $1584-1594$

[40] E. Butler, et al., Adaptive changes in pancreatic beta cell fractional area and beta cell turnover in human pregnancy, Diabetologia 53 (2010) 2167-2176.

[41] N. Sakata, et al., Efficacy comparison between intraportal and subcapsular islet transplants in a murine diabetic model, Transpl. Proc. 41 (2009) 346-349.

[42] R.M. Jindal, R.A. Sidner, H.B. Mcdaniel, M.S. Johnson, S.E. Fineberg, Intraportal vs kidney subcapsular site for human pancreatic islet transplantation, Transpl. Proc. 1345 (1998) 398-399.

[43] T. Kin, et al., The use of an approved biodegradable polymer scaffold as a solid support system for improvement of islet engraftment, Artif. Organs 32 (2008) 990-993.

[44] A.R. Pepper, B. Gala-Lopez, O. Ziff, M.J. Shapiro, Revascularization of transplanted pancreatic islets and role of the transplantation site, Clin. Dev. Immunol. 2013 (2013) 352315.

[45] P. Buchwald, et al., Quantitative assessment of islet cell products: estimating the accuracy of the existing protocol and accounting for islet size distribution, Cell Transpl. 18 (2009) 1223-1235.

[46] Robert B. Vernon, Anton Preisinger, Michel D. Gooden, Leonard A. D'Amico, Betty B. Yue, Paul L. Bollyky, Christian S. Kuhr, Thomas R. Hefty, Gerald T. Nepom, J. Gebe, Reversal of diabetes in mice with a bioengineered islet implant incorporating a type I collagen hydrogel and sustained release of vascular endothelial growth factor, Cell Transpl. 21 (2012) 1-21.

[47] S. Sokic, M. Christenson, J. Larson, G. Papavasiliou, In situ generation of cellladen porous MMP-sensitive PEGDA hydrogels by gelatin leaching, Macromol. Biosci. 14 (2014) 731-739.

[48] T. Canal, N.A. Peppas, Correlation between mesh size and equilibrium degree of swelling of polymeric networks, J. Biomed. Mater Res. 23 (1989) $1183-1193$.

[49] B.N. Brown, B.D. Ratner, S.B. Goodman, S. Amar, S.F. Badylak, Macrophage polarization: an opportunity for improved outcomes in biomaterials and regenerative medicine, Biomaterials 33 (2012) 3792-3802.

[50] X. Chen, et al., The epididymal fat pad as a transplant site for minimal islet mass, Transplantation 84 (2007) 122-125.

[51] A.N. Bashkatov, et al., Glucose and mannitol diffusion in human dura mater, Biophys. J. 85 (2003) 3310-3318.

[52] A.N. Bashkatov, et al., Estimation of Glucose Diffusion Coefficient in Scleral Tissue, vol. 4001, 2000, pp. 345-355.

[53] B. Vasir, et al., Hypoxia induces vascular endothelial growth factor gene and protein expression in cultured rat islet cells, Diabetes 47 (1998) 1894-1903.

[54] M. Brissova, et al., Pancreatic islet production of vascular endothelial growth factor-A is essential for islet vascularization, revascularization, and function, Diabetes 55 (2006) 2974-2985.

[55] L. Orci, R.H. Unger, Functional subdivision of islets of Langerhans and possible role of D cells, Lancet 306 (1975) 1243-1244.

[56] K. Bloch, J. Vennäng, D. Lazard, P. Vardi, Different susceptibility of rat pancreatic alpha and beta cells to hypoxia, Histochem Cell Biol. 137 (2012) $801-810$.

[57] F. Esni, et al., Neural cell adhesion molecule (N-CAM) is required for cell type segregation and normal ultrastructure in pancreatic islets, J. Cell Biol. 144 (1999) 325-337.

[58] H.S. Spijker, et al., Conversion of mature human $\beta$-cells into glucagon- 
producing $\alpha$-cells, Diabetes 62 (2013) 2471-2480.

[59] C. Talchai, S. Xuan, H.V. Lin, L. Sussel, D. Accili, Pancreatic $\beta$ cell dedifferentiation as a mechanism of diabetic $\beta$ cell failure, Cell 150 (2012) 1223-1234.

[60] I.A. Valdez, A.K.K. Teo, R.N. Kulkarni, Cellular Stress Drives Pancreatic Plasticity, 2015, p. 7

[61] E. Pedraza, M.M. Coronel, C.A. Fraker, C. Ricordi, C.L. Stabler, Preventing hypoxia-induced cell death in beta cells and islets via hydrolytically activated, oxygen-generating biomaterials, Proc. Natl. Acad. Sci. U. S. A. 109 (2012) 4245-4250.

[62] D.M. Salvay, et al., Extracellular matrix protein-coated scaffolds promote the reversal of diabetes after extrahepatic islet transplantation, Transplantation 85 (2008) 1456-1464.

[63] X. Xiao, et al., M2 macrophages promote beta-cell proliferation by upregulation of SMAD7, Proc. Natl. Acad. Sci. U. S. A. 111 (2014) E1211-E1220. 